\title{
Local Origin of Mesenchymal Cells in a Murine Orthotopic Lung Transplantation Model of Bronchiolitis Obliterans
}

Takeshi Mimura, ${ }^{*}$ Natalie Walker, ${ }^{*}$ Yoshiro Aoki, ${ }^{*}$ Casey M. Manning, ${ }^{*}$ Benjamin J. Murdock, ${ }^{*}$ Jeffery L. Myers, ${ }^{\dagger}$ Amir Lagstein, John J. Osterholzer, * and Vibha N. Lama*

From the Division of Pulmonary and Critical Care Medicine, * Department of Internal Medicine, and the Department of Pathology, ${ }^{\dagger}$ University of Michigan Health System, Ann Arbor, Michigan

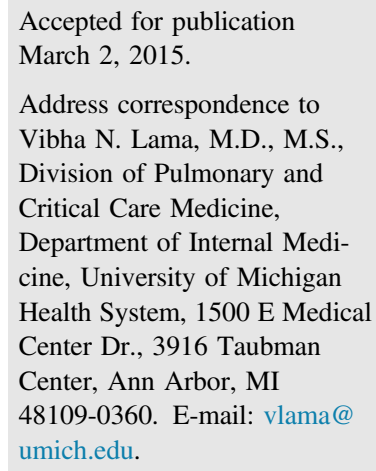

\begin{abstract}
Bronchiolitis obliterans is the leading cause of chronic graft failure and long-term mortality in lung transplant recipients. Here, we used a novel murine model to characterize allograft fibrogenesis within a whole-lung microenvironment. Unilateral left lung transplantation was performed in mice across varying degrees of major histocompatibility complex mismatch combinations. B6D2F1/J (a cross between C57BL/6J and DBA/2J) (Haplotype $\mathrm{H} 2 \mathrm{~b} / \mathrm{d}$ ) lungs transplanted into $\mathrm{DBA} / 2 \mathrm{~J}(\mathrm{H} 2 \mathrm{~d})$ recipients were identified to show histopathology for bronchiolitis obliterans in all allogeneic grafts. Time course analysis showed an evolution from immune cell infiltration of the bronchioles and vessels at day 14, consistent with acute rejection and lymphocytic bronchitis, to subepithelial and intraluminal fibrotic lesions of bronchiolitis obliterans by day 28 . Allografts at day 28 showed a significantly higher hydroxyproline content than the isografts $(33.21 \pm 1.89$ versus $22.36 \pm 2.33 \mu \mathrm{g} / \mathrm{mL})$. At day 40 the hydroxyproline content had increased further $(48.91 \pm 7.09 \mu \mathrm{g} / \mathrm{mL})$. Flow cytometric analysis was used to investigate the origin of mesenchymal cells in fibrotic allografts. Collagen I-positive cells $(89.43 \% \pm 6.53 \%)$ in day 28 allografts were $\mathrm{H} 2 \mathrm{Db}$ positive, showing their donor origin. This novel murine model shows consistent and reproducible allograft fibrogenesis in the context of single-lung transplantation and represents a major step forward in investigating mechanisms of chronic graft failure. (Am J Pathol 2015, 185: 1564-1574; http://dx.doi.org/10.1016/j.ajpath.2015.03.002)
\end{abstract}

Bronchiolitis obliterans (BO), a fibroproliferative process targeting the small airways of the lung, is the predominant cause of chronic graft failure and poor long-term outcomes after lung transplantation. $^{1-3} \mathrm{BO}$ is also a common complication after allogeneic hematopoietic stem-cell transplantation. At present, no therapeutic options are available to prevent the development of or slow the progression of $\mathrm{BO} .^{1-3}$

Airway remodeling of $\mathrm{BO}$, marked by mesenchymal cell infiltration and collagen deposition, evolves in a complex milieu marked by interactions of infiltrating recipient-derived cells and graft-resident somatic cells. Peribronchiolar mononuclear inflammation (also known as lymphocytic bronchiolitis) ${ }^{4-6}$ and episodes of acute rejection (AR) marked by perivascular inflammation ${ }^{7-11}$ precede the development of BO. Both T and B lymphocytes are important, suggesting a role for cellmediated and humoral immunity. ${ }^{12-15}$ Allo-immune injury also is implicated, with evidence of collagen $\mathrm{V}$-specific cellular immunity noted before BO development. ${ }^{16}$ The epithelium is an important target of these immune responses ${ }^{17-20}$ and epithelial cell injury precedes the ensuing mesenchymal cell recruitment and activation. ${ }^{21}$ However, in vivo investigations into the mechanisms of allograft fibrogenesis in a whole-lung milieu are hampered by the lack of a robust and reproducible murine model of $\mathrm{BO}$ and allograft fibrosis. $^{22-24}$ The commonly used heterotopic tracheal transplantation model relies on the investigation of fibrosis

Supported by NIH grants R01 HL118017 and R01 HL094622 (V.N.L.), the Scleroderma Research Foundation Award (V.N.L.), the Brian and Mary Campbell and Elizabeth Campbell Carr research gift fund (V.N.L.), and a Merit Review Award from the Biomedical Laboratory Research \& Development Service, US Department of Veterans Affairs (J.J.O.).

Disclosures: None declared.

Current address of T.M., Department of Surgical Oncology, Hiroshima University, Hiroshima, Japan 
in an isolated trachea placed in an extrapulmonary environment. ${ }^{23} \mathrm{~A}$ significant concern here is the applicability of findings from this tracheal transplant model to a whole-lung microenvironment and the need to target the mesenchymal cell population specifically responsible for matrix deposition and fibrotic remodeling in the transplanted lung. Human investigations, although limited by technical aspects, suggest that locally resident cells are the primary mesenchymal cell populations in a transplanted lung and contribute to fibrogenesis, ${ }^{25,26}$ mesenchymal cells in the tracheal transplant model show a recipient origin and focus attention on cells such as fibrocytes. ${ }^{27-29}$ Thus, a wholelung transplant model, which allows investigation into the origin of mesenchymal cells at the single-cell level in a fibrotic lung allograft and mimics human disease, is needed.

In this study we investigated fibrogenesis in whole-lung allografts transplanted across varying degrees of major histocompatibility complex (MHC) mismatch. We show a model using a transplant from F1 hybrid into a parent mouse that reproducibly shows $\mathrm{BO}$ with, evolution from moderate $\mathrm{AR}$ and lymphocytic bronchitis to airway and vascular fibrosis. Furthermore, we investigated the origin of the mesenchymal cell population in whole-lung allografts at a single-cell level and show that the collagen I-positive population in a fibrotic lung allograft is predominantly of donor origin.

\section{Materials and Methods}

\section{Animals and Orthotopic Lung Transplant Model}

Specific pathogen-free male inbred mice B6D2F1/J (H2b/d), DBA/2J (H2d), C57BL/6 (H2b), C57BL10 (H2b), and CB6F1/J (H2b/d) were purchased from Jackson Laboratories (Bar Harbor, ME). All mice (age, 8 to 12 weeks; weight, 24 to $30 \mathrm{~g}$ ) were used as both donors and recipients. Syngeneic transplants were performed in the C57BL/10 lungs $\rightarrow \mathrm{C} 57 \mathrm{BL} / 10, \quad \mathrm{C} 57 \mathrm{BL} / 6 \quad$ lungs $\rightarrow \mathrm{C} 57 \mathrm{BL} / 6$, and $\mathrm{B} 6 \mathrm{D} 2 \mathrm{~F} 1 / \mathrm{J}$ lungs $\rightarrow \mathrm{B} 6 \mathrm{D} 2 \mathrm{~F} 1 / \mathrm{J}$ strain combinations, and allogeneic transplants were performed in the C57BL/10 lungs $\rightarrow \mathrm{C} 57 \mathrm{BL} / 6$, C57BL/6 lungs $\rightarrow \mathrm{CB} 6 \mathrm{~F} 1 / \mathrm{J}$, and B6D2F1/J lungs $\rightarrow \mathrm{DBA} / 2 \mathrm{~J}$ strain combinations. All experiments were performed according to the protocols approved by the University Committee on the Use and Care of Animals at the University of Michigan. Orthotopic left lung transplantations were performed using a previously described technique. ${ }^{30-32}$ A surgical microscope (SZX16-SZX2; Olympus Center Valley, PA) with $\times 2.1$ to $\times 34.5$ magnifications was used for all procedures. Buprenorphine was given to recipient mice at the conclusion of the procedure and again every 12 hours until 3 days after transplant. No immunosuppressive drugs were used.

\section{Histopathologic Evaluation of Orthotopic Lung Transplantation}

The mice were euthanized humanely under anesthesia at 7 , 14,28 , and 40 days after transplantation. The heart-lung block was fixed in $10 \%$ formalin and embedded in paraffin. Cut sections were stained with hematoxylin and eosin or Masson's trichrome stain to determine the presence of fibrosis in BO lesions. Grading for rejection pathology was performed by blinded reviewers using standard criteria developed by the Lung Rejection Study Group. ${ }^{33}$ To detect infiltration of lymphocytes or macrophages and to evaluate epithelial injury and fibrosis, immunohistochemical staining was performed according to standard clinical laboratory procedures using the following primary antibodies: rabbit anti-CD3 polyclonal antibody (1:500; Abcam, Cambridge, MA), rat anti-F4/80 (1:750; Thermo Scientific, Rockford, IL), and rabbit anticlub cell secretory protein (CCSP) (1:2000; Abcam). Masson's trichrome stain was performed to visualize collagen and fibrosis using the NovaUltra Masson's Trichrome Stain Kit (IHC World, Woodstock, MD).

\section{Flow Cytometric Analysis}

Multiparameter flow cytometric analysis was used to quantify inflammatory cell infiltration and to investigate the origin of collagen-expressing cells in the transplanted lungs. For inflammatory cell quantitation, single-cell suspensions enriched for lung leukocytes were obtained from enzymatically digested lungs (perfused, not lavaged), stained with antibody, and assessed by flow cytometric analysis using established gating strategies to identify specific leukocyte subsets. ${ }^{34,35}$ Initial gates eliminated debris and selected for $\mathrm{CD} 5^{+}$leukocytes.

To identify lymphocyte subsets, gates were set on small cells [forward-scattered light (FSC) ${ }^{\text {low }}$ side-scattered light $(\mathrm{SSC})^{\text {low }}$ ] and subsequent gating identified $\mathrm{CD} 4^{+} \mathrm{T}$ cells $\left(\mathrm{CD}^{+}\right), \mathrm{CD}^{+} \mathrm{T}$ cells $\left(\mathrm{CD}^{+}\right)$, and B cells $\left(\mathrm{CD} 19^{+}\right)$. To identify myeloid cells, initial gates eliminated $\mathrm{CD}^{+}$and $\mathrm{CD} 19^{+}$lymphocytes and Ly- $6 \mathrm{G}^{+}$granulocytes. Subsequent gates identified $\mathrm{CD} 11 \mathrm{~b}^{+}$dendritic cells (FSC ${ }^{\text {moderate/high }}$ nonautofluorescent $\left.\quad \mathrm{CD} 11 \mathrm{c}^{+} \quad \mathrm{CD} 11 \mathrm{~b}^{+}\right)$, monocyte-derived exudate macrophages (FSC ${ }^{\text {high }}$ autofluorescent $\mathrm{CD} 11 \mathrm{c}^{+}$ $\mathrm{CD}_{1} 1 \mathrm{~b}^{+}$), and resident alveolar macrophages (FSC ${ }^{\text {high }}$ autofluorescent $\mathrm{CD} 11 \mathrm{c}^{+} \mathrm{CD} 11 \mathrm{~b}^{-}$). Total cell numbers were obtained by multiplying the cell frequency by the total number of $\mathrm{CD} 45^{+}$leukocytes for each lung. To investigate collagen/ $\mathrm{H} 2 \mathrm{D}^{\mathrm{b}}$-expressing cells, transplanted lungs were digested enzymatically and strained to obtain a single-cell suspension. Cells $\left(1 \times 10^{6}\right)$ were blocked by Mouse BD Fc Block $(1: 100$; 24G2, BD Pharmingen, San Jose, CA) for 30 minutes on ice, followed by staining for $\mathrm{H}_{2} \mathrm{D}^{\mathrm{b}}$ with an AlexaFluor 647-conjugated antibody (1:50 dilution, Biolegend, Inc., San Diego, CA) or for 30 minutes on ice.

After surface staining, cells were fixed and permeabilized with Cytofix/Cytoperm solution from the Cytofix/Cytoperm kit (BD Biosciences, San Jose, CA) according to the manufacturer's protocol. After fixation and permeabilization, cells were stained with rabbit anti-collagen I antibody $(1: 100$; Rockland, Inc., Gilbertsville, PA) or nonspecific rabbit IgG for 30 minutes on ice (Jackson Immunoresearch, West 
Grove, PA). Cells then were washed with Cytofix/Cytoperm buffer and incubated with donkey anti-rabbit phycoerythrin-conjugated secondary antibody (1:200; Jackson Immunoresearch) for 30 minutes on ice. Cells then were washed and resuspended in fluorescence-activated cell sorting buffer before flow cytometric analysis. In separate experiments, staining with phycoerythrin rat anti-mouse CD184 (CXCR4) or anti-mouse CD326 (epithelial cell adhesion molecule) was performed along with collagen.

\section{Morphometric Analysis}

Small-airway remodeling was quantified using the previously established subepithelial connective tissue volume density (VVsub) method. VVsub measurements were defined as the difference in the area, delimited by the basement membrane and the outer edge of the airway adventitia, divided by the length of the subepithelial basement membrane ${ }^{36,37}$ Measurements were performed on trichrome-stained tissue sections, which clearly demarcated the epithelium and basement membrane from subepithelial connective tissue.

On hematoxylin and eosin-stained tissue sections, the conventional point counting method ${ }^{38}$ was used to quantitate the open airway lumens within a lung field. All slides were reviewed and scored in a blinded manner by a clinical pathologist with expertise in evaluating lung histology (J.L.M.). A 24-mm straight line interrupted counting reticle composed of 21 lines and 42 points (Merz KR-821) was inserted into a $10 \times$ eyepiece (WS10X/22; Olympus) and used to examine four sections at specific depths from lung blocks using a $4 \times$ objective (UPlanFL $4 \times / 0.13$; Olympus), for a total magnification of $\times 40\left(23.75 \mathrm{~mm}^{2} /\right.$ field $)$ in a multihead Olympus BX51 microscope. Airways were identified by the combination of an appropriately shaped lumen, a wall that included smooth muscle fibers, and a columnar epithelial lining. Fields for analysis were selected from the middle of whole-lung sections, aligning the top of the reticle with the parietal pleura in each case. The number of points intersecting airway lumens in the graft and native lung in the same section were counted and expressed as a fraction.

\section{Hydroxyproline Quantification}

Lung explants were homogenized in $0.5 \mathrm{~mL}$ of phosphatebuffered saline; $0.5 \mathrm{~mL}$ of $12 \mathrm{~N} \mathrm{HCl}$ was added to the homogenate and the samples were hydrolyzed at $120^{\circ} \mathrm{C}$ for 24 hours. Five microliters of each sample was combined with $5 \mu \mathrm{L}$ citrate/ acetate buffer $(238 \mathrm{mmol} / \mathrm{L}$ citric acid, $1.2 \%$ glacial acetic acid, $532 \mathrm{mmol} / \mathrm{L}$ sodium acetate, and $85 \mathrm{mmol} / \mathrm{L}$ sodium hydroxide) in a 96-well plate. Samples were incubated with $100 \mu \mathrm{L}$ of chloramine T solution $(0.282 \mathrm{~g}$ chloramine $\mathrm{T}$ to $16 \mathrm{~mL}$ of citrate/ acetate buffer, $2.0 \mathrm{~mL}$ of n-propanol, and $2.0 \mathrm{~mL}$ double distilled $\mathrm{H}_{2} \mathrm{O}$ ) for 30 minutes at room temperature. After this incubation, $100 \mu \mathrm{L}$ of Ehrlich's reagent (2.5 g para-dimethylaminobenzaldehyde added to $9.3 \mathrm{~mL}$ of n-propanol and $3.9 \mathrm{~mL}$ of $70 \%$ perchloric acid) was added, and the samples were incubated at $65^{\circ} \mathrm{C}$ for 30 minutes. The absorbance of each sample then was measured at $550 \mathrm{~nm}$. Standard curves for the experiment were generated using known concentrations of the hydroxyproline reagent (Sigma-Aldrich, St. Louis, MO).

\section{Statistical Analysis}

The Student's $t$-test was used to determine $P$ values when comparing two groups. When comparing three or more groups, analysis of variance was performed with a post hoc Bonferroni test to determine which groups showed significant differences. $P<0.05$ was considered significant.

\section{Results}

\section{Histology of Lung Grafts Transplanted across Varied Histocompatibility Combinations of Donor and Recipient}

Mice transplanted across the same inbred species (isografts) showed long-term graft acceptance. Strains that were disparate at MHC antigen loci $(\mathrm{H} 2 \mathrm{~b}$ to $\mathrm{H} 2 \mathrm{~d}, \mathrm{BALB} / \mathrm{c}$ to $\mathrm{C} 57 \mathrm{BL} / 6)$ developed severe AR within 7 days after transplantation, causing complete destruction of the lung and preventing the evaluation of $\mathrm{BO}$ as described previously by others. ${ }^{39}$ Transplantation across minor histocompatibility mismatched pairs, C57BL/10 to C57BL/6 (H-2b to H-2b), was studied based on the previous literature. ${ }^{40,41}$ C57BL/10 allografts placed into C57BL/6 lungs showed scattered areas of lymphocytic infiltration in bronchovascular bundles at day 14 , but only minimal subepithelial fibrosis was noted (Figure 1A). This led us to investigate pairs with moderate MHC mismatch similar to what has been used to model chronic graft-versus-host disease in the field of bone marrow transplantation. One murine model that has been used to study graft-versus-host disease is the injection of parental cells into F1 recipients. ${ }^{42-44}$ In an attempt to keep C57BL/6 as the donor species, we transplanted C57BL/6 (H2b) lungs into $\mathrm{CB} 6 \mathrm{~F} 1 / \mathrm{J}$ (a cross between $\mathrm{C} 57 \mathrm{BL} / 6$ and $\mathrm{BALB} / \mathrm{c}$ ) $(\mathrm{H}-\mathrm{b} / \mathrm{d})$ recipients. These grafts showed no significant rejection, and the lung was accepted without any evidence of $\mathrm{BO}$ (Figure 1A). However, transplantation of B6D2F1/J [a cross between C57BL/6J and DBA/2J (H2b/d)] lungs into DBA/2J (H2d) recipients, a pair commonly used to model chronic graftversus-host disease, ${ }^{45}$ showed the development of BO and graft fibrosis in all recipients by day 28 (Figure 1A). All further investigations were performed using this combination model.

Time Course of Histologic Changes in the B6D2F1/J to DBA/2J Lung Transplant Model

Histology was evaluated at days $7,14,28$, and 40 after transplantation in isografts (DBA/2J to DBA/2J) and allografts (B6D2F1/J to DBA/2J) (Figure 1B). Isografts showed normal histology at all of the time points. Allografts showed mild mononuclear cell infiltration in the perivascular and peribronchial areas at day 7. At day 14 after transplantation, marked 
A

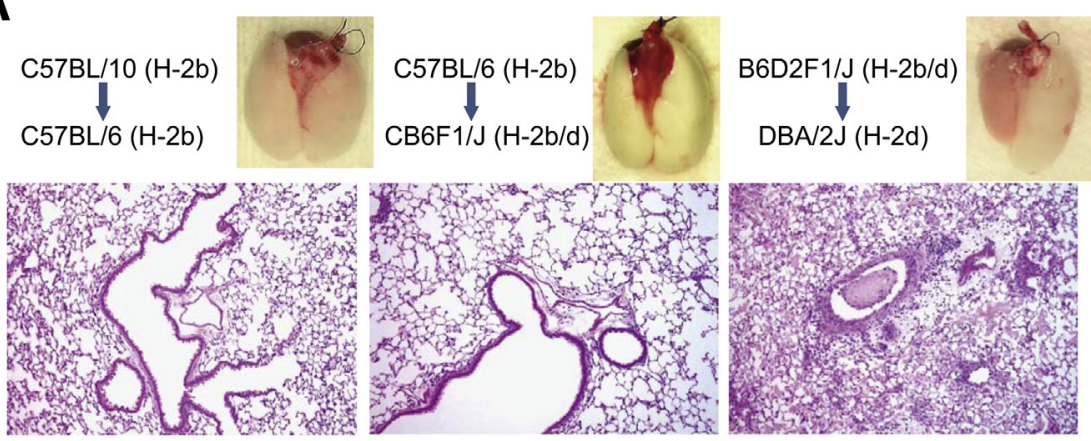

B

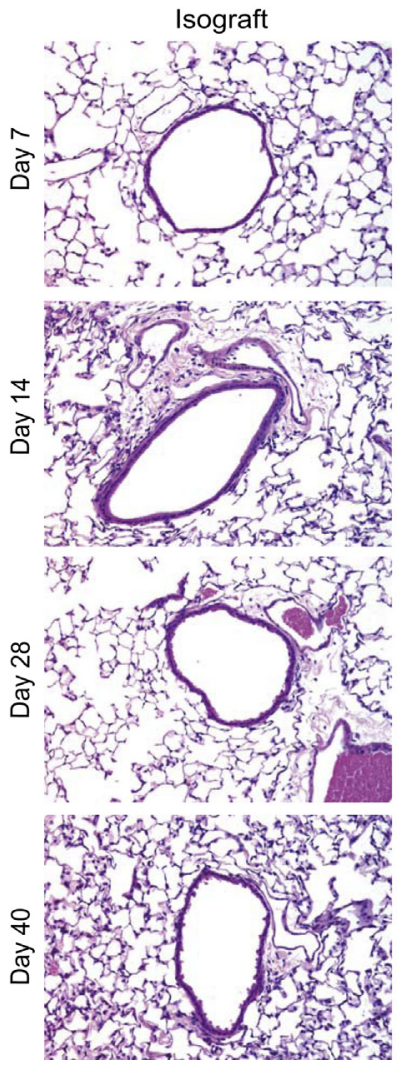

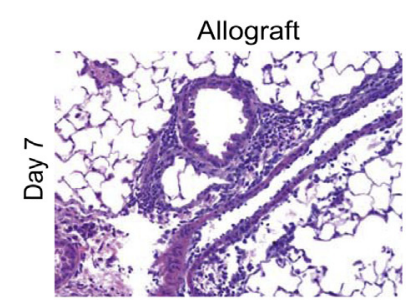
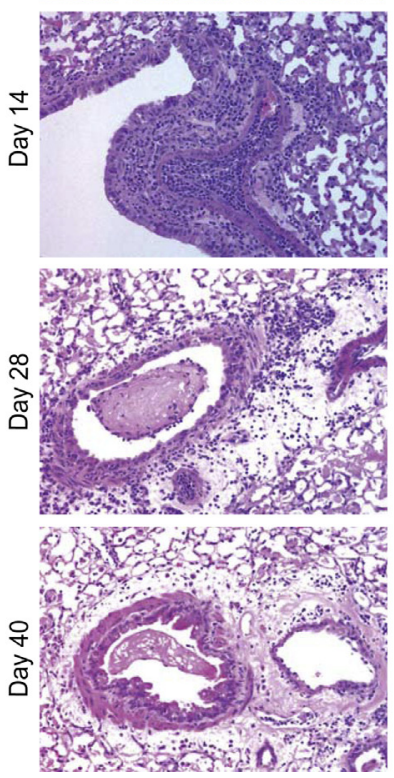

Figure 1 Development of bronchiolitis obliterans in murine lung allografts. A: Comparison of murine lung allografts transplanted across varying degrees of major histocompatibility complex mismatch. Representative gross anatomy and hematoxylin and eosin images at day 28 after transplant. B: Time course of histologic changes. Histopathology of isografts (DBA/2J to $\mathrm{DBA} / 2 \mathrm{~J})$ and allografts (B6D2F1/J to DBA/2J) studied at various time points (days 7, 14, 28, and 40) after transplantation. Changes consistent with mild acute rejection and lymphocytic bronchitis (mononuclear cell infiltration in the perivascular and peribronchial areas) were noted at day 7. Day 14 images show marked perivascular, intraluminal, and peribronchial infiltrate of lymphocytes, neutrophils, and some eosinophils; intraepithelial lymphocytic infiltration also is noted. Epithelial denudation with subepithelial fibrosis is seen at day 28. This section also shows intraluminal fibrosis in the airway. Bronchiolitis obliterans with peribronchial fibrosis, smooth muscle hypertrophy, and luminal narrowing is seen in allografts at day 40 . Isografts showed normal histology at all time points. Original magnification: $\times 40($ A) $; \times 200(B)$. perivascular and intraluminal infiltrate of lymphocytes, neutrophils, and some eosinophils was noted along with evidence of endothelial damage. Marked lymphocytic bronchitis also was noted with peribronchial and intraepithelial inflammatory infiltration and epithelial cell hypertrophy and death. By day 28 after transplantation, perivascular and peribronchial fibrosis was noted along with evidence of fibrinous exudate or fibrotic plugs in the lumen. A further increase in collagen, smooth muscle hypertrophy, and luminal narrowing was noted in allografts at day 40 .

\section{Characterization of the Infiltrating Immune Cell Populations in Lung Allografts}

Immunohistochemical staining for CD3 and F4/80 was performed to identify $\mathrm{T}$ lymphocytes and macrophages, respectively, at various time points after lung transplantation in allografts (Figure 2A). Infiltrating mononuclear phagocytes and $\mathrm{CD}^{+}{ }^{+}$lymphocytes were seen in peribronchial and perivascular distribution in allografts at all time points with increases in infiltration from days 7 to 14. Further quantitative investigation of the infiltrating immune cell populations was performed using flow cytometric analysis at days 14 and 28 (Figure 2B). A threefold increase in total CD45-positive leukocytes was noted in allografts at day 14 compared with isografts. Both $\mathrm{CD}^{+}$and $\mathrm{CD}^{+} \mathrm{T}$ cells were markedly higher in allografts at day 14 and showed persistence at day 28. An increase in B $\left(\mathrm{CD} 19^{+}\right)$cells was noted in allografts at day 28. Antigen-presenting cells, including dendritic cells, exudate macrophages, and alveolar macrophages, also were studied. Both CD11b-positive dendritic cells and 
A
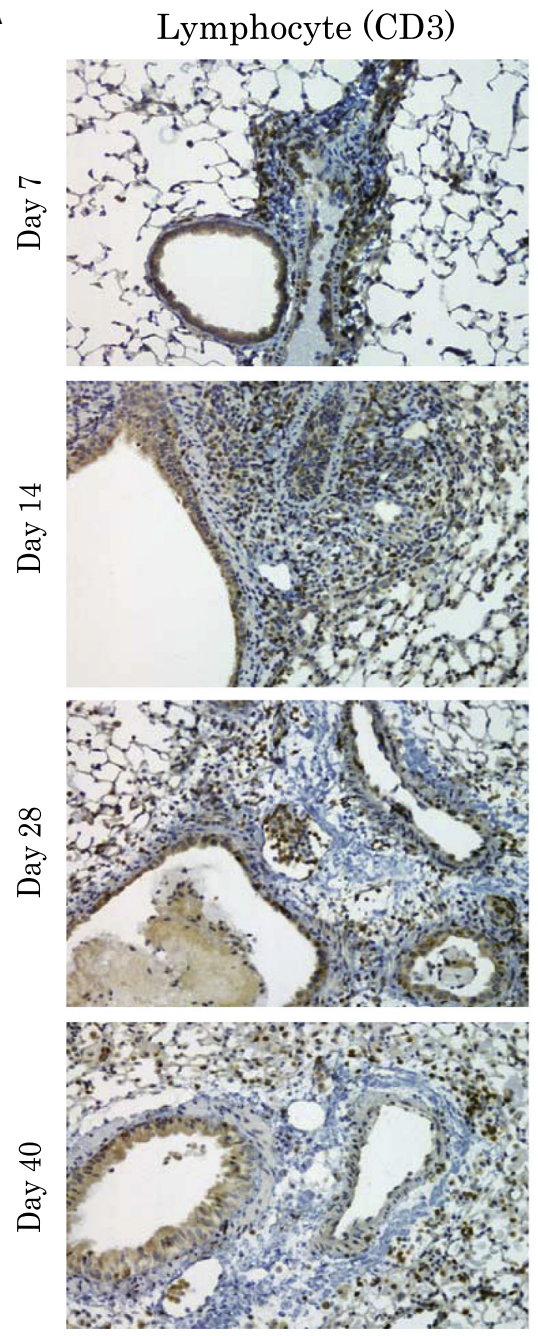

B

B CD45+ lung leukocytes CD4+ T cells
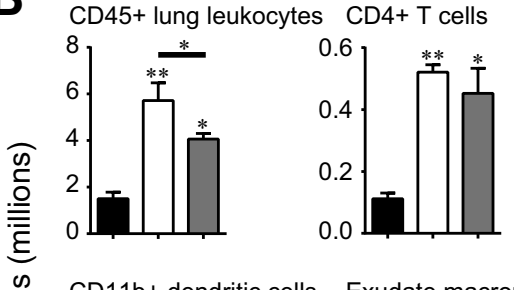
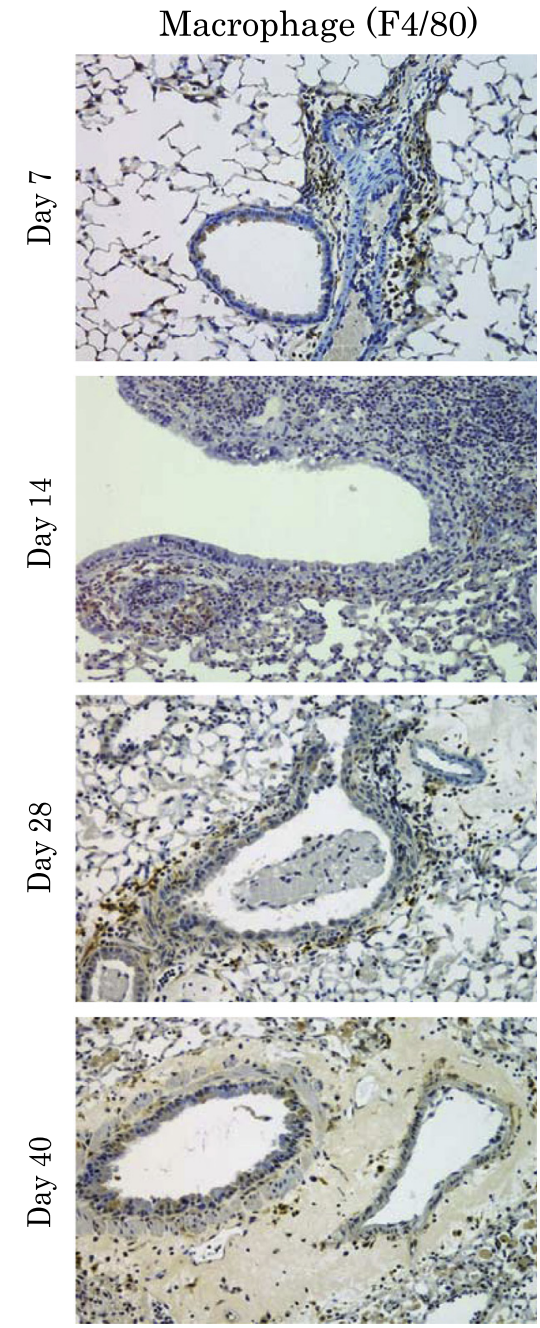

CD8+ T cells
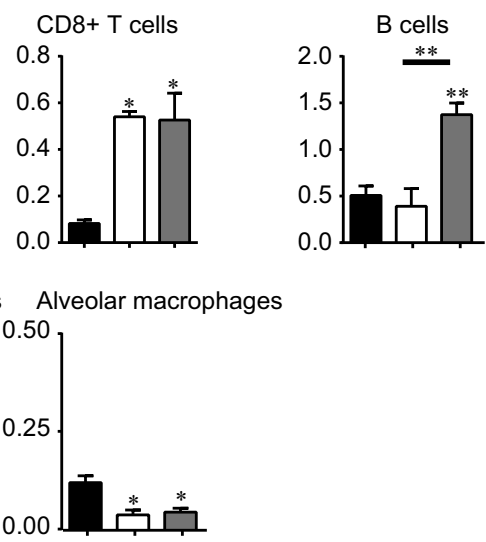

Figure 2 Characterization of kinetic changes in immune cell infiltration in the transplanted lung grafts. A: Immunohistochemical staining for T cells (CD3) and macrophages (F4/80) in the allograft (B6D2F1/J to DBA/2J) model at various time points (days 7, 14, 28, and 40) after transplantation. T-cell and macrophage infiltration of the peribronchiolar area is noted along with perivascular and intraluminal infiltration. B: Immunophenotyping of infiltrating immune cell populations in allografts (B6D2F1/J to $\mathrm{DBA} / 2 \mathrm{~J})$. Single-cell suspension of day 14 isografts ( $n=3$; black bars), day 14 allografts $(n=3$; white bars), and day 28 allografts ( $n=4$; grey bars) were stained and analyzed by flow cytometric analysis to quantitate infiltrating $\mathrm{CD}_{4} 5^{+}$leukocytes, $\mathrm{CD}^{+} \mathrm{T}$ cells $\left(\mathrm{CD}^{+}\right), \mathrm{CD}^{+} \mathrm{T}$ cells $\left(\mathrm{CD} 8^{+}\right)$, and B cells $\left(\mathrm{CD} 19^{+}\right)$. To identify myeloid cells, initial gates eliminated $\mathrm{CD}^{+}$ and $\mathrm{CD} 19^{+}$lymphocytes and $\mathrm{Ly}-6 \mathrm{G}^{+}$granulocytes. Subsequent gates identified $\mathrm{CD} 11 \mathrm{~b}^{+}$dendritic cells ( $\mathrm{FSC}^{\text {moderate/high }}$ nonautofluorescent $\mathrm{CD} 11 \mathrm{c}^{+} \mathrm{CD} 11 \mathrm{~b}^{+}$), monocyte-derived exudate macrophages (FSC ${ }^{\text {high }}$

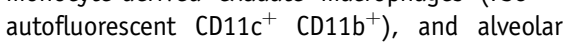
macrophages (FSC high autofluorescent $\mathrm{CD}^{\text {h1 }} \mathrm{c}^{+}$ $\left(\mathrm{CD} 11 \mathrm{~b}^{-}\right)$. Total cell numbers were obtained by multiplying the cell frequency by the total number of $\mathrm{CD} 5^{+}$leukocytes for each lung. ${ }^{*} P<0.05$, ${ }^{*} P<0.01$. All comparisons were made with isografts other than when specified by the bar below the asterisk. Original magnification: $\times 200($ A) .
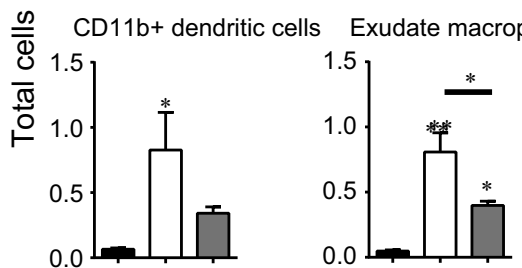

exudative macrophages showed a significant increase at day 14 . At day 28 , the number of exudative macrophages still was greater than that observed in isografts, but decreased relative to their numbers noted at day 14. Alveolar macrophages, on the other hand, showed a persistent decrease in their numbers in the allografts compared with isografts.

\section{Airway Epithelial Cell Injury in Rejecting Lung Allografts}

In the mouse, club cells are the major cell type of bronchiolar epithelia. Staining with club cell secretory protein (CCSP) was used to study epithelial changes over time in the airways of the lung allografts (Supplemental Figure S1). Isografts showed 
normal CCSP expression in airway epithelium. CCSP expression was maintained in the bronchial epithelium in allografts at day 7. At day 14, significant epithelial hypertrophy with patchy loss of CCSP staining was noted. By day 40, epithelium was denuded and CCSP expression was decreased significantly, suggesting a loss of secretory club cells.

\section{Evaluation of Fibrosis in the B6D2F1/J to DBA/2J Orthotopic Lung Transplant Model}

Masson's trichrome stain and the hydroxyproline assay were used to evaluate the collagen content in the transplanted lungs. A time course of collagen expression in allografts is shown in Figure 3A. At day 28, peribronchial and perivascular trichrome staining was noted in the majority of the bronchovascular bundles. Furthermore, trichrome staining in intraluminal fibrous plugs also was identified. At day 40, dense peribronchial collagen staining with luminal narrowing was noted in the allografts. Quantification of collagen in the grafts was performed by the hydroxyproline assay (Figure 3B). Allografts at day 28 showed a significantly higher hydroxyproline content than the isografts (means $\pm \mathrm{SEM}$; of $33.21 \pm 1.89$ $\mu \mathrm{g} / \mathrm{mL}$ versus $22.36 \pm 2.33 \mu \mathrm{g} / \mathrm{mL}$ ). At day 40 , the hydroxyproline content had increased further $(48.91 \pm 7.09 \mu \mathrm{g} /$ $\mathrm{mL}$ ) and was statistically higher compared with both the isografts and day 28 allografts.

A morphometric analysis of allografts was performed to investigate penetrance (the percentage of airways developing remodeling) and consistency (the percentage of allograft showing airway fibrosis and obliteration). Airway wall remodeling was evaluated by VVsub, a well-used parameter of airway wall thickness. ${ }^{36,37}$ Distribution of VVsub in individual grafts is shown in Figure 4A. Increased VVsub $(>20 \mu \mathrm{m})$ was noted in $>80 \%$ of the airways in B6D2F1/J to DBA/2J allografts, and all transplanted lungs showed airway remodeling. In comparison, only $14 \%$ of the airways in C57BL/10 to C57BL/6 allografts showed increased VVsub. The conventional point counting method ${ }^{38}$ was used for morphometric analysis of airway obliteration in the transplanted lungs. The ratio of points that were within the airway lumen in graft versus native lung was quantified blindly in four separate sections for each transplant (Figure 4B). The ratio in isografts ranged between 1 and 1.5. A significantly decreased ratio $(<0.5)$ was seen in all B6D2F1/J to DBA/2J allografts, showing a decreased luminal area. High variability again was noted among C57BL/10 to C57BL/6 allografts. These data show that all transplanted allografts in the B6D2F1/J to DBA/2J model develop airway remodeling, which is significantly more robust than the previously used C57BL/10 to C57BL/6 model.

\section{Origin of Mesenchymal Cells in Fibrotic Lung Allografts}

The expression of $\mathrm{H} 2 \mathrm{Db}$ was used to investigate donor versus recipient origin of the mesenchymal cell population in these murine lung allografts. Flow cytometry of single-cell suspension from the DBA/2J, B6D2F1/J, and C57BL/6J lungs are
A
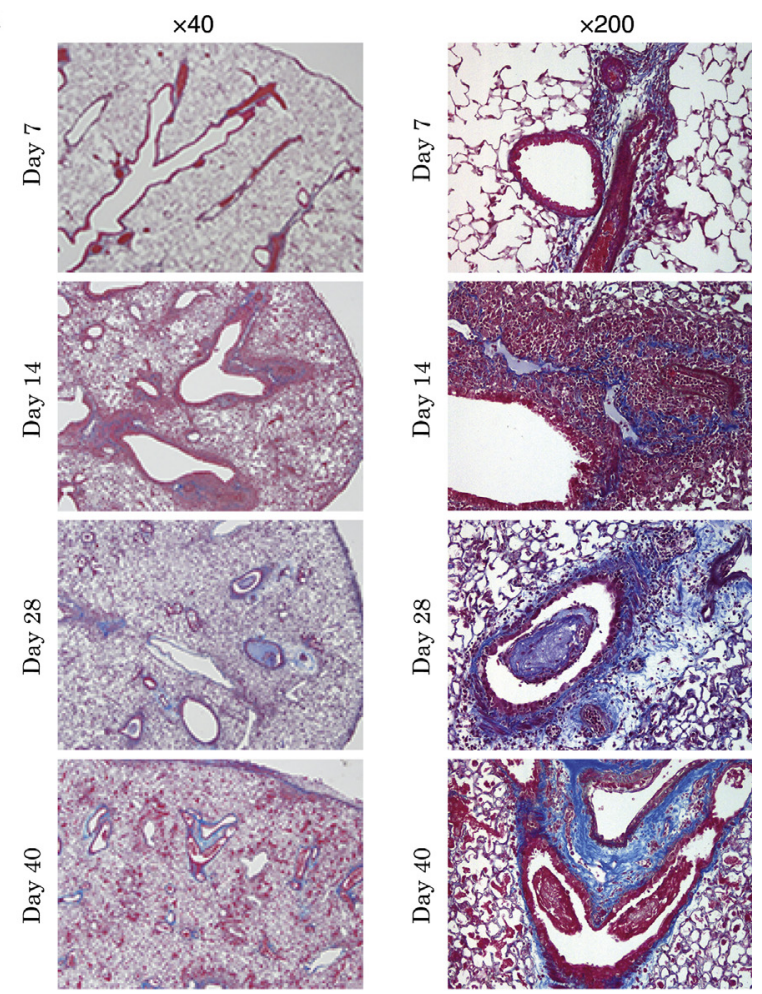

B

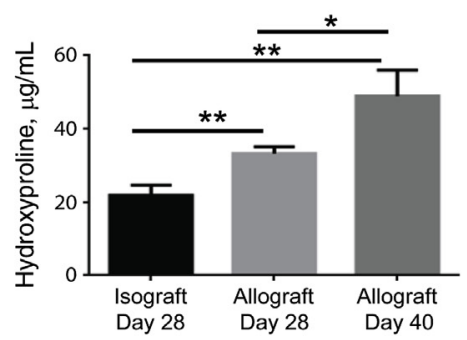

Figure 3 Time course of fibrogenesis in the lung allografts. A: Masson's trichrome staining was used to evaluate collagen expression in lung sections. Representative images of the allografts (B6D2F1/J to DBA/2J) at indicated time points after transplantation. Collagen staining (blue) is noted, centered around the airways and vessels, by day 28 . Subepithelial collagen expression is noted in both the larger and the smaller terminal bronchioles. Some airways show intraluminal collagen expressing fibrous plugs. Collagen appears denser at day 40. B: Collagen content quantitation by hydroxyproline assay. Lung grafts were harvested on specified days and analyzed for hydroxyproline content. Results are reported as the mean concentration $(\mu \mathrm{g} / \mathrm{mL}) \pm$ SEM $(n=3$ to 5 mice in each group with experiments repeated in duplicates). ${ }^{*} P<0.05,{ }^{* *} P<0.01$.

shown in Figure 4C. DBA/2J (H2-d) animals, which are the recipient species, lacked expression of the $\mathrm{H} 2 \mathrm{Db}$ antigen. In contrast, B6D2F1/J [a cross between C57BL/6J and DBA/2J (H2-b/d)] donor lungs showed expression of H2Db by flow cytometric analysis similar to that seen in pure C57BL/6J animals. Expression of $\mathrm{H} 2 \mathrm{Db}$ on collagen-expressing cells then was analyzed in the native and transplanted lungs from the B6D2F1/J to DBA/2J transplants at day 28 (Figure 4C). Collagen I-positive cells in the native lungs were, as expected, H2Db-negative. In the grafts, $89.43 \% \pm 6.53 \%$ of collagen I-positive cells were H2Dd positive, showing their 
A

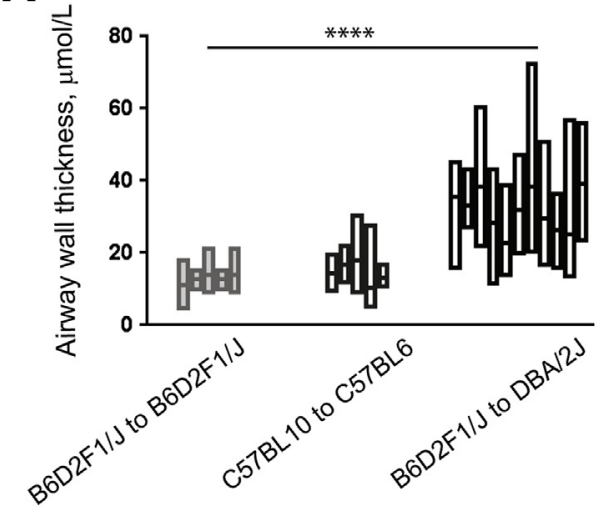

B

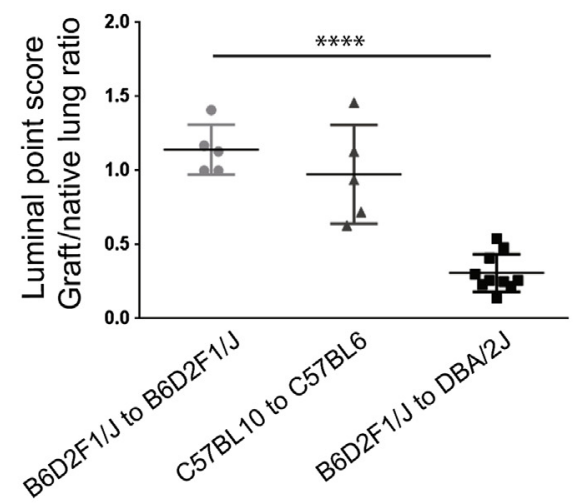

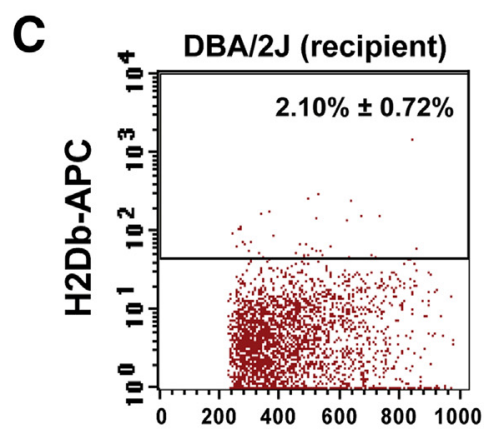
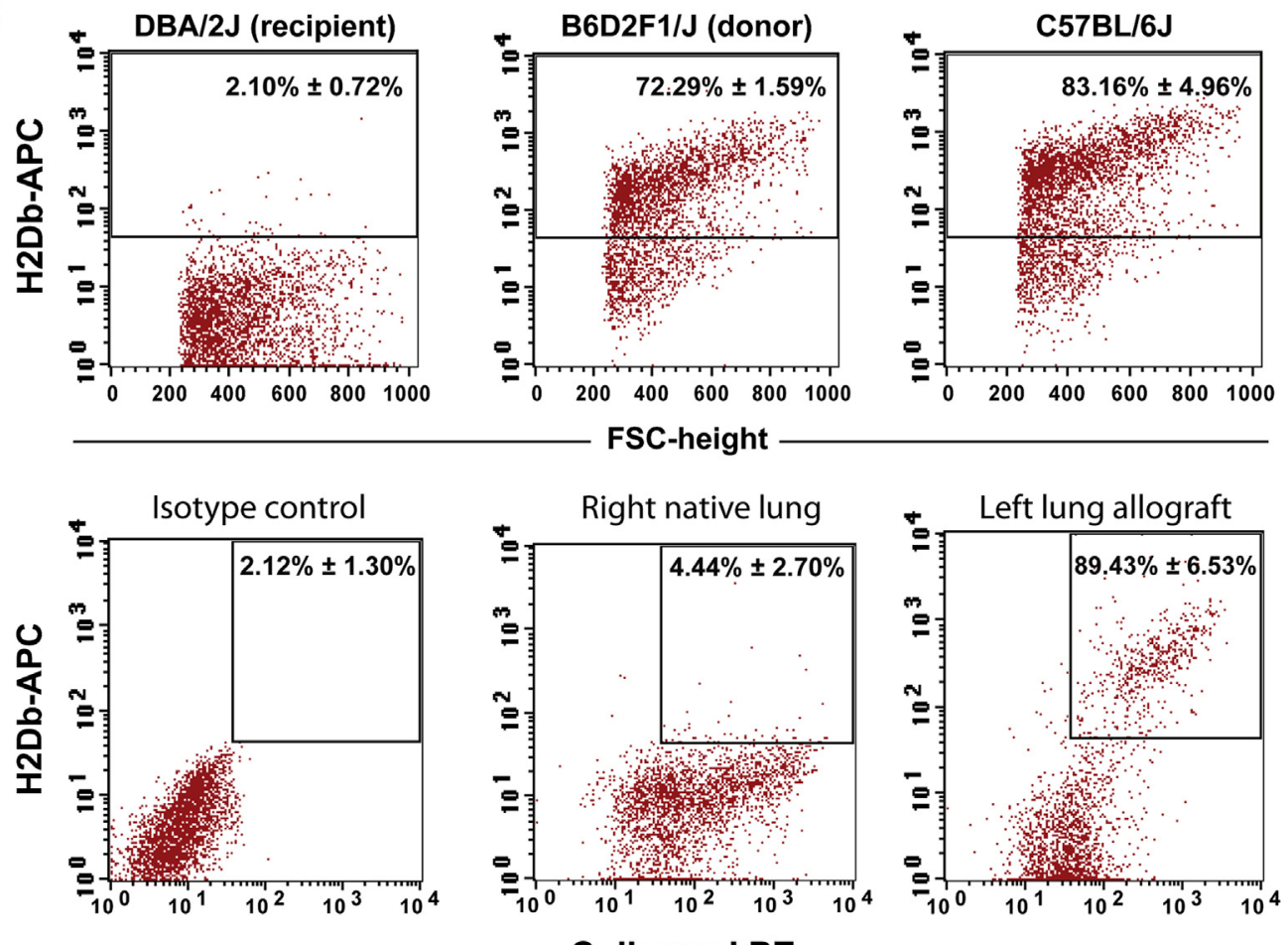

Collagen I PE

Figure 4 Morphometric assessment and determination of donor versus recipient origin of collagen-expressing cells in the lung grafts. A: Morphometric analysis of airway wall thickness in transplanted lungs. The difference in the area, delimited by the basement membrane and the outer edge of the airway adventitia, divided by the length of subepithelial basement membrane, was measured for all airways in lung sections from individual grafts. Data from each individual graft are shown as floating bars from minimum to maximum, with a line at the mean. Data from five isografts (B6D2F1/J to B6D2F1/J), five minor major histocompatibility complex mismatch transplants (C57BL10 to C57BL6), and $10 \mathrm{~F} 1$ to parent transplants (B6D2F1/J to DBA/2J). B: Morphometric analysis of airway obliteration in transplanted lungs. A conventional point counting method was used to quantitate open airway lumens in a lung field. The number of points intersecting airway lumens in the graft and native lung in the same section were counted and expressed as a fraction. Data from each individual transplanted mouse are shown as the mean of the data from four separate fields. $N=5$ isografts, $5 \mathrm{C} 57 \mathrm{BL} / 10$ to $\mathrm{C} 57 \mathrm{BL} / 6$ allografts, and $10 \mathrm{~B} 6 \mathrm{D} 2 \mathrm{~F} 1 / \mathrm{J}$ to DBA/2J allografts. C: Donor origin of collagen-expressing cells in fibrotic lung allografts. Unilateral left lung transplantation was performed with B6D2F1/J [a cross between C57BL/6J (H2-Db) and DBA/2J (H2-Dd)] as donors and DBA/2J (H2-Dd) as recipients. Flow cytometric analysis for expression of $\mathrm{H} 2-\mathrm{Db}$, a major histocompatibility complex class I molecule expressed only in donor mouse in this combination, was used to investigate donor versus recipient origin of collagen-expressing cells in the allografts. Flow cytometric analysis of single-cell suspension of the lungs from the three species confirms a lack of $\mathrm{H} 2$-Db expression in the recipients and its positive expression in the donor B6D2F1/J lungs. Expression of $\mathrm{H} 2$ - $\mathrm{Db}$ on collagen-expressing cells was quantified in native lungs and allografts at day 28. Collagen ${ }^{+}$cells are predominantly H2-Db positive in the allografts. $n=3$ transplanted animals. $* \star \star * P<0.0001$. APC, allophycocyanin; FSC, forward side scatter; PE, phycoerythrin.

donor origin. Collagen I-positive cells from transplanted lungs also were found to be uniformly epithelial cell adhesion molecule negative $(98.88 \% \pm 0.15 \%)$, as well as CXCR4 negative $(99.05 \% \pm 0.05 \%)$ (data not shown).

\section{Discussion}

Lung transplantation has the worst outcome among all solid organ transplantations, with 5- and 10-year survival rates of 
approximately $53 \%$ and $31 \%$, respectively. ${ }^{46}$ The most common pathology noted in chronically failing lung allografts is subepithelial or intraluminal fibrosis of the small airways or BO. ${ }^{1}$ Human translational studies have allowed for the identification of immune and nonimmune pathways that contribute to the final common pathway of fibrosis. ${ }^{47}$ However, investigation into the mechanisms of mesenchymal cell infiltration and activation in whole-lung allograft has been limited by the lack of reproducible and robust animal models. ${ }^{22-24}$

Here, we report a novel murine model of $\mathrm{BO}$ in the context of orthotopic single-lung transplantation using transplantation of F1 (B6D2F1/J) into the parent (DBA/2J) strain. These grafts, which are discordant with the recipient at the $\mathrm{H} 2 \mathrm{Db}$ locus, show an evolution from mild to moderate vascular and airway rejection to well-established peribronchial and perivascular fibrosis by 4 weeks, allowing for investigation of allograft fibrosis within the physiological stretch and air-permissive dynamics of a whole lung. We show that fibrosis is persistent and progressive, is noted in all transplanted lungs, and that, similar to human lungs, mesenchymal cells in the fibrotic allografts show a predominantly donor origin. These features make this novel orthotopic lung transplant model of BO wellsuited to investigate the mechanisms of fibroproliferation within the lung grafts and for preclinical studies of potential antifibrotic therapeutic compounds in $\mathrm{BO}$ after lung transplantation.

Heterotopic tracheal transplantation, in which donor trachea is placed in extrapulmonary sites such as the skin, is the most common murine model used to investigate $\mathrm{BO} .{ }^{48}$ This model reproducibly shows evolution from immune cell infiltration to fibrotic luminal obliteration and hence is the preferred model for studying fibrogenesis mechanisms. However, studying an isolated cartilaginous airway does not allow for investigation into cellular interactions in a complex lung milieu. ${ }^{22-24}$ Orthotopic single-lung transplantation offers a more anatomically relevant model and has been shown recently to be technically feasible in mice. ${ }^{32}$ Syngeneic grafts are accepted with normal histology. Severe AR develops in allogeneic lungs transplanted across major MHC mismatch, allowing investigation only within shorter time frames. ${ }^{32}$ Recent studies using combinations of minor histocompatibility antigen mismatched pairs ${ }^{40}$ or immunosuppression in fully MHC antigenmismatched combinations, ${ }^{49}$ have shown the ability to limit the degree of AR and generate fibrotic lesions. However, the development of fibrotic airway lesions was not consistent, and was noted in a small number of airways in less than half of the allografted lungs. ${ }^{23,24,31,32}$

Several unique features in this specific murine model of lung transplantation lend it to investigations of immuneinjury-mediated lung fibrosis and chronic graft failure after lung transplantation. First, fibrosis was found to target lung airways and vessels, similar to what is noted predominately in chronically failing lung allografts. A robust histologic pattern of $\mathrm{BO}$ was noted with peribronchial and intraluminal fibrosis of the airways. Vascular fibrosis and sclerosis also was a predominant feature of this model. Such changes have been described well in chronically failing human lung allografts. ${ }^{33,50}$ Second, fibrosis developing in the context of immune injury in this model was noted to be progressive, as shown by increased collagen expression from days 28 to 40 by quantitative hydroxyproline assay. This is significant because in other fibrotic lung models, such as a single time point bleomycin injection, regression of fibrosis was noted over time. ${ }^{51}$ Third, fibrotic changes were noted consistently in all allografted lungs in this $\mathrm{B} 6 \mathrm{D} 2 \mathrm{~F} 1 / \mathrm{J}$ lungs $\rightarrow \mathrm{DBA} / 2 \mathrm{~J}$ strain combination, as reflected by morphometric analysis, making this a reproducible model to investigate potential therapeutic targets.

MHC disparate donor-recipient pairs have been used in murine bone marrow transplantation to model graft-versushost disease, and recently in murine lung transplantation. In pioneering work in this arena, Fan et $\mathrm{al}^{40}$ were the first to show $\mathrm{BO}$ lesions in lungs transplanted across minor histocompatibility antigens in a specific C57BL/10 to C57BL/6 combination. BO was noted to be confined to few airways and was noted in less than half of allografted lungs. Surprisingly, the number of grafts showing lesions of $\mathrm{BO}$ was lower at 28 days (44\%) than at 21 days $(60 \%)$. This combination was tested in the present study and scattered lymphocytic infiltration with minimal subepithelial fibrosis was noted. However, robust fibrotic lesions were not obtained and significant variability was noted, limiting the ability to exploit this combination to study fibroproliferative pathways. In comparison, the $\mathrm{B} 6 \mathrm{D} 2 \mathrm{~F} 1 / \mathrm{J}$ lungs $\rightarrow \mathrm{DBA} / 2 \mathrm{~J}$ strain combination showed consistent fibrotic remodeling involving a majority of the airways, and the difference in fibrosis between isografts and allografts was shown by quantitative hydroxyproline assay and morphometric analysis. Immunosuppression was not used in this model because the degree of rejection was moderate and allowed the lungs to be viable, unlike that noted in major MHC mismatch pairs. Immunosuppression in MHC class I mismatched murine lung transplants has been investigated previously by De Vleeschauwer et al. ${ }^{49}$ BO lesions were noted at much later time points in only a third of the allografted lungs. It is possible that immunosuppression might be needed as an adjunct therapy in an investigation of novel targets in our moderate MHC mismatch model.

This model allows us to follow the kinetics of progression to BO within a whole lung. Histology showed evolution from immune cell infiltration to epithelial cell injury and the development of fibrosis over time. Although maximal inflammatory cell infiltration along the bronchovascular bundles was noted on histology at 14 days, flow cytometric analysis showed a continuing presence of $\mathrm{T}$ cells and, interestingly, an increase in the B-cell population at day 28. Along with $\mathrm{T}$ cells, B lymphocytes have been implicated previously in the development of airway fibrosis in other murine models. ${ }^{12-15}$ Evidence of epithelial injury was noted in murine allografts starting at day 7 , and showed progressive worsening with evidence of apoptotic and dysplastic epithelial and endothelial cells along with loss of CCSPpositive cells. Bronchial epithelium has been noted to be damaged and dysmorphic in human biopsy samples with 
BOS, ${ }^{3}$ and decreases in CCSP expression have been seen in transplanted lungs in BOS. ${ }^{52}$

A significant finding of this study was the demonstration that the collagen-expressing cells in the lung allograft undergoing fibrogenesis were derived predominantly from the donor lung. A total of $89.43 \% \pm 6.53 \%$ of the collagen Iexpressing cells at day 28 in the allografts showed expression of the $\mathrm{H} 2 \mathrm{Db}$ antigen, which was shown to be absent on cells from the recipient DBA/J2 mice. The origin of effector mesenchymal cells in tissue fibrosis has been an arena of active investigation secondary to the potential contribution from the bone marrow via fibrocytes or mesenchymal stem cell populations. ${ }^{53-55}$ There has been similar ambivalence about the relative contribution of the tissue-resident versus bone marrow-derived mesenchymal compartment to fibrotic remodeling of the allograft in the field of lung transplantation. In heterotopic tracheal transplant models, mesenchymal cells have been shown to be derived from the recipient rather than the donor, ${ }^{29}$ and the fibrocyte population is being investigated. ${ }^{27,28}$ Similar findings of recipient derivation of mesenchymal cells was suggested in an intrapulmonary tracheal transplant model of BO using immunofluorescent staining. ${ }^{56}$ The contrary finding of the predominant donor origin of collagen I-expressing cells in murine lung allografts in the present study could reflect the investigation of fibrosis in a whole-lung allograft rather than in an isolated trachea. Furthermore, our investigation used studies at a single-cell level, which eliminated the potential misinterpretation that can arise from studying cells in a complex tissue en bloc by immunostaining. ${ }^{57}$

The role of donor cells in lung allograft fibrosis has been investigated in humans. Mesenchymal cells derived from bronchoalveolar lavage of human lung allografts show donor origin even years after transplant. ${ }^{25}$ Furthermore, histologic fibrotic lesions in human transplanted lungs were shown to express transcription factors unique to lung-resident populations of mesenchymal cells. ${ }^{26}$ Of note, these human studies were limited to mesenchymal cells in specific compartments. The murine lung transplant model of $\mathrm{BO}$ allows for investigation of the mesenchymal cell population in the entire allograft at a single-cell level, thus strengthening and advancing previous findings in humans. Along with their donor origin, collagen I-expressing cells in the allograft were epithelial cell adhesion molecule negative and hence likely represent the resident mesenchymal cell population. However, our investigation did not rule out potential transdifferentiation of these collagen I-positive epithelial cell adhesion molecule negative from other resident lung somatic cells. In summary, the findings from this murine orthotopic lung transplant model of BO further underscores the need to target mechanisms by which resident lung somatic cells contribute to lung fibrogenesis and also confirms the applicability of this model by showing its similarity to human disease.

In summary, we present a robust reproducible model of BO in murine single-lung transplantation and show the contribution of graft resident cells to fibrogenesis. The ability to follow fibrosis evolution with a whole-lung microenvironment and to use genetically altered mice makes this a powerful tool to investigate mechanistic interactions of immune cell populations with resident graft somatic cells within a lung allograft. Furthermore, the high penetrance and consistency of airway fibrosis in this model lends itself to preclinical investigations using potential novel therapeutic targets.

\section{Supplemental Data}

Supplemental material for this article can be found at http://dx.doi.org/10.1016/j.ajpath.2015.03.002.

\section{References}

1. Barker AF, Bergeron A, Rom WN, Hertz MI: Obliterative bronchiolitis. N Engl J Med 2014, 370:1820-1828

2. Estenne M, Hertz MI: Bronchiolitis obliterans after human lung transplantation. Am J Respir Crit Care Med 2002, 166:440-444

3. Estenne M, Maurer JR, Boehler A, Egan JJ, Frost A, Hertz M, Mallory GB, Snell GI, Yousem S: Bronchiolitis obliterans syndrome 2001: an update of the diagnostic criteria. J Heart Lung Transplant 2002, 21:297-310

4. Scott AI, Sharples LD, Stewart S: Bronchiolitis obliterans syndrome: risk factors and therapeutic strategies. Drugs 2005, 65: 761-771

5. Sharples LD, McNeil K, Stewart S, Wallwork J: Risk factors for bronchiolitis obliterans: a systematic review of recent publications. J Heart Lung Transplant 2002, 21:271-281

6. Husain AN, Siddiqui MT, Holmes EW, Chandrasekhar AJ, McCabe M, Radvany R, Garrity ER: Analysis of risk factors for the development of bronchiolitis obliterans syndrome. Am J Respir Crit Care Med 1999, 159:829-833

7. Davis WA, Finlen Copeland CA, Todd JL, Snyder LD, Martissa JA, Palmer SM: Spirometrically significant acute rejection increases the risk for BOS and death after lung transplantation. Am J Transplant 2012, 12:745-752

8. Burton CM, Iversen M, Carlsen J, Mortensen J, Andersen CB, Steinbruchel D, Scheike T: Acute cellular rejection is a risk factor for bronchiolitis obliterans syndrome independent of posttransplant baseline FEV1. J Heart Lung Transplant 2009, 28: 888-893

9. Hachem RR, Khalifah AP, Chakinala MM, Yusen RD, Aloush AA, Mohanakumar T, Patterson GA, Trulock EP, Walter MJ: The significance of a single episode of minimal acute rejection after lung transplantation. Transplantation 2005, 80:1406-1413

10. Khalifah AP, Hachem RR, Chakinala MM, Yusen RD, Aloush A Patterson GA, Mohanakumar T, Trulock EP, Walter MJ: Minimal acute rejection after lung transplantation: a risk for bronchiolitis obliterans syndrome. Am J Transplant 2005, 5:2022-2030

11. Heng D, Sharples LD, McNeil K, Stewart S, Wreghitt T, Wallwork J: Bronchiolitis obliterans syndrome: incidence, natural history, prognosis, and risk factors. J Heart Lung Transplant 1998 , $17: 1255-1263$

12. Fukami N, Ramachandran S, Takenaka M, Weber J, Subramanian V, Mohanakumar T: An obligatory role for lung infiltrating B cells in the immunopathogenesis of obliterative airway disease induced by antibodies to MHC class I molecules. Am J Transplant 2012, 12: 867-876

13. Jaramillo A, Fernandez FG, Kuo EY, Trulock EP, Patterson GA, Mohanakumar T: Immune mechanisms in the pathogenesis of bronchiolitis obliterans syndrome after lung transplantation. Pediatr Transplant 2005, 9:84-93 
14. Srinivasan M, Flynn R, Price A, Ranger A, Browning JL, Taylor PA, Ritz J, Antin JH, Murphy WJ, Luznik L, Shlomchik MJ, PanoskaltsisMortari A, Blazar BR: Donor B-cell alloantibody deposition and germinal center formation are required for the development of murine chronic GVHD and bronchiolitis obliterans. Blood 2012, 119: $1570-1580$

15. Xue J, Zhu X, George MP, Myerburg MM, Stoner MW, Pilewski JW, Duncan SR: A human-mouse chimeric model of obliterative bronchiolitis after lung transplantation. Am J Pathol 2011, 179:745-753

16. Burlingham WJ, Love RB, Jankowska-Gan E, Haynes LD, Xu Q, Bobadilla JL, Meyer KC, Hayney MS, Braun RK, Greenspan DS, Gopalakrishnan B, Cai J, Brand DD, Yoshida S, Cummings OW, Wilkes DS: IL-17-dependent cellular immunity to collagen type V predisposes to obliterative bronchiolitis in human lung transplants. J Clin Invest 2007, 117:3498-3506

17. Glanville AR, Tazelaar HD, Theodore J, Imoto E, Rouse RV, Baldwin JC, Robin ED: The distribution of MHC class I and II antigens on bronchial epithelium. Am Rev Respir Dis 1989, 139: 330-334

18. Mauck KA, Hosenpud JD: The bronchial epithelium: a potential allogeneic target for chronic rejection after lung transplantation. J Heart Lung Transplant 1996, 15:709-714

19. Reznik SI, Jaramillo A, Zhang L, Patterson GA, Cooper JD, Mohanakumar T: Anti-HLA antibody binding to hla class I molecules induces proliferation of airway epithelial cells: a potential mechanism for bronchiolitis obliterans syndrome. J Thorac Cardiovasc Surg 2000, 119:39-45

20. Taylor PM, Rose ML, Yacoub MH: Expression of MHC antigens in normal human lungs and transplanted lungs with obliterative bronchiolitis. Transplantation 1989, 48:506-510

21. Ikonen TS, Brazelton TR, Berry GJ, Shorthouse RS, Morris RE: Epithelial re-growth is associated with inhibition of obliterative airway disease in orthotopic tracheal allografts in nonimmunosuppressed rats. Transplantation 2000, 70:857-863

22. De Vleeschauwer S, Vanaudenaerde B, Vos R, Meers C, Wauters S, Dupont L, Van Raemdonck D, Verleden G: The need for a new animal model for chronic rejection after lung transplantation. Transplant Proc 2011, 43:3476-3485

23. Jungraithmayr W, Jang JH, Schrepfer S, Inci I, Weder W: Small animal models of experimental obliterative bronchiolitis. Am J Respir Cell Mol Biol 2013, 48:675-684

24. Sato M, Keshavjee S, Liu M: Translational research: animal models of obliterative bronchiolitis after lung transplantation. Am J Transplant 2009, 9:1981-1987

25. Lama VN, Smith L, Badri L, Flint A, Andrei AC, Murray S, Wang Z, Liao H, Toews GB, Krebsbach PH, Peters-Golden M, Pinsky DJ, Martinez FJ, Thannickal VJ: Evidence for tissue-resident mesenchymal stem cells in human adult lung from studies of transplanted allografts. J Clin Invest 2007, 117:989-996

26. Walker N, Badri L, Wettlaufer S, Flint A, Sajjan U, Krebsbach PH, Keshamouni VG, Peters-Golden M, Lama VN: Resident tissue-specific mesenchymal progenitor cells contribute to fibrogenesis in human lung allografts. Am J Pathol 2011, 178: 2461-2469

27. Gillen JR, Zhao Y, Harris DA, Lapar DJ, Stone ML, Fernandez LG, Kron IL, Lau CL: Rapamycin blocks fibrocyte migration and attenuates bronchiolitis obliterans in a murine model. Ann Thorac Surg 2013, 95:1768-1775

28. Harris DA, Zhao Y, LaPar DJ, Emaminia A, Steidle JF, Stoler M, Linden J, Kron IL, Lau CL: Inhibiting CXCL12 blocks fibrocyte migration and differentiation and attenuates bronchiolitis obliterans in a murine heterotopic tracheal transplant model. J Thorac Cardiovasc Surg 2013, 145:854-861

29. Jordan JL, Hurley CL, Lee TD, Hirsch GM: Recipient cells form the proliferative lesion in the rat heterotopic tracheal allograft model of obliterative airway disease. J Heart Lung Transplant 2003, 22: $357-360$
30. Jungraithmayr W, Weder W: The technique of orthotopic mouse lung transplantation as a movie-improved learning by visualization. Am J Transplant 2012, 12:1624-1626

31. Krupnick AS, Lin X, Li W, Okazaki M, Lai J, Sugimoto S, Richardson SB, Kornfeld CG, Garbow JR, Patterson GA, Gelman AE, Kreisel D: Orthotopic mouse lung transplantation as experimental methodology to study transplant and tumor biology. Nat Protoc 2009, 4:86-93

32. Okazaki M, Krupnick AS, Kornfeld CG, Lai JM, Ritter JH, Richardson SB, Huang HJ, Das NA, Patterson GA, Gelman AE, Kreisel D: A mouse model of orthotopic vascularized aerated lung transplantation. Am J Transplant 2007, 7:1672-1679

33. Stewart S, Fishbein MC, Snell GI, Berry GJ, Boehler A, Burke MM, Glanville A, Gould FK, Magro C, Marboe CC, McNeil KD, Reed EF, Reinsmoen NL, Scott JP, Studer SM, Tazelaar HD, Wallwork JL, Westall G, Zamora MR, Zeevi A, Yousem SA: Revision of the 1996 working formulation for the standardization of nomenclature in the diagnosis of lung rejection. J Heart Lung Transplant 2007, 26: $1229-1242$

34. Osterholzer JJ, Milam JE, Chen GH, Toews GB, Huffnagle GB, Olszewski MA: Role of dendritic cells and alveolar macrophages in regulating early host defense against pulmonary infection with Cryptococcus neoformans. Infect Immun 2009, 77:3749-3758

35. Osterholzer JJ, Olszewski MA, Murdock BJ, Chen GH, ErbDownward JR, Subbotina N, Browning K, Lin Y, Morey RE, Dayrit JK, Horowitz JC, Simon RH, Sisson TH: Implicating exudate macrophages and Ly-6C(high) monocytes in CCR2-dependent lung fibrosis following gene-targeted alveolar injury. J Immunol 2013 , 190:3447-3457

36. Hogg JC, Chu F, Utokaparch S, Woods R, Elliott WM, Buzatu L, Cherniack RM, Rogers RM, Sciurba FC, Coxson HO, Pare PD: The nature of small-airway obstruction in chronic obstructive pulmonary disease. N Engl J Med 2004, 350:2645-2653

37. Polosukhin VV, Cates JM, Lawson WE, Zaynagetdinov R, Milstone AP, Massion PP, Ocak S, Ware LB, Lee JW, Bowler RP, Kononov AV, Randell SH, Blackwell TS: Bronchial secretory immunoglobulin a deficiency correlates with airway inflammation and progression of chronic obstructive pulmonary disease. Am J Respir Crit Care Med 2011, 184:317-327

38. Hanak V, Ryu JH, de Carvalho E, Limper AH, Hartman TE, Decker PA, Myers JL: Profusion of fibroblast foci in patients with idiopathic pulmonary fibrosis does not predict outcome. Respir Med 2008, 102:852-856

39. Okazaki M, Gelman AE, Tietjens JR, Ibricevic A, Kornfeld CG, Huang HJ, Richardson SB, Lai J, Garbow JR, Patterson GA, Krupnick AS, Brody SL, Kreisel D: Maintenance of airway epithelium in acutely rejected orthotopic vascularized mouse lung transplants. Am J Respir Cell Mol Biol 2007, 37:625-630

40. Fan L, Benson HL, Vittal R, Mickler EA, Presson R, Fisher AJ, Cummings OW, Heidler KM, Keller MR, Burlingham WJ, Wilkes DS: Neutralizing IL-17 prevents obliterative bronchiolitis in murine orthotopic lung transplantation. Am J Transplant 2011, 11: 911-922

41. Suzuki H, Fan L, Wilkes DS: Development of obliterative bronchiolitis in a murine model of orthotopic lung transplantation. J Vis Exp 2012, 10:65

42. Pestalozzi BC, Zinkernagel RM: Graft-versus-host reactions in F1 hybrid mice: MHC-restriction-independent generalized depression of virus-specific cytotoxic T cell response. Immunobiology 1984, 166 : 308-317

43. Puliaev RA, Puliaeva IA, Ryan AE, Via CS: The parent-into-F1 model of graft-vs-host disease as a model of in vivo T cell function and immunomodulation. Curr Med Chem Immunol Endocr Metab Agents 2005, 5:575-583

44. Sprangers B, Van Wijmeersch B, Luyckx A, Sagaert X, Verbinnen B, Rutgeerts O, Lenaerts C, Tousseyn T, Dubois B, Waer M, 
Billiau AD: Subclinical GvHD in non-irradiated F1 hybrids: severe lymphoid-tissue GvHD causing prolonged immune dysfunction. Bone Marrow Transplant 2011, 46:586-596

45. Fast LD: $\mathrm{DBA} / 2 \mathrm{~J}$ and $\mathrm{DBA} / 2 \mathrm{Ha}$ lymphocytes differ in their ability to induce graft-vs-host disease. J Immunol 1989, 143: 2489-2493

46. Yusen RD, Christie JD, Edwards LB, Kucheryavaya AY, Benden C, Dipchand AI, Dobbels F, Kirk R, Lund LH, Rahmel AO, Stehlik J; International Society for Heart and Lung Transplantation: The Registry of the International Society for Heart and Lung Transplantation: thirtieth Adult Lung and Heart-Lung Transplant Report-2013; focus theme: age. J Heart Lung Transplant 2013, 32: 965-978

47. Belperio JA, Weigt SS, Fishbein MC, Lynch JP 3rd: Chronic lung allograft rejection: mechanisms and therapy. Proc Am Thorac Soc 2009, 6:108-121

48. Hertz MI, Jessurun J, King MB, Savik SK, Murray JJ: Reproduction of the obliterative bronchiolitis lesion after heterotopic transplantation of mouse airways. Am J Pathol 1993, 142: $1945-1951$

49. De Vleeschauwer S, Jungraithmayr W, Wauters S, Willems S, Rinaldi M, Vaneylen A, Verleden S, Willems-Widyastuti A, Bracke K, Brusselle G, Verbeken E, Van Raemdonck D, Verleden G, Vanaudenaerde B: Chronic rejection pathology after orthotopic lung transplantation in mice: the development of a murine BOS model and its drawbacks. PLoS One 2012, 7:e29802

50. Yousem SA, Berry GJ, Cagle PT, Chamberlain D, Husain AN, Hruban RH, Marchevsky A, Ohori NP, Ritter J, Stewart S,
Tazelaar HD: Revision of the 1990 working formulation for the classification of pulmonary allograft rejection: Lung Rejection Study Group. J Heart Lung Transplant 1996, 15:1-15

51. B Moore B, Lawson WE, Oury TD, Sisson TH, Raghavendran K, Hogaboam CM: Animal models of fibrotic lung disease. Am J Respir Cell Mol Biol 2013, 49:167-179

52. Kelly FL, Kennedy VE, Jain R, Sindhwani NS, Finlen Copeland CA, Snyder LD, Eu JP, Meltzer EB, Brockway BL, Pavlisko E, Stripp BR, Palmer SM: Epithelial clara cell injury occurs in bronchiolitis obliterans syndrome after human lung transplantation. Am J Transplant 2012, 12:3076-3084

53. Bucala R, Spiegel LA, Chesney J, Hogan M, Cerami A: Circulating fibrocytes define a new leukocyte subpopulation that mediates tissue repair. Mol Med 1994, 1:71-81

54. Hinz B, Phan SH, Thannickal VJ, Galli A, Bochaton-Piallat ML, Gabbiani G: The myofibroblast: one function, multiple origins. Am J Pathol 2007, 170:1807-1816

55. Pittenger MF, Mackay AM, Beck SC, Jaiswal RK, Douglas R, Mosca JD, Moorman MA, Simonetti DW, Craig S, Marshak DR: Multilineage potential of adult human mesenchymal stem cells. Science 1999, 284:143-147

56. Sato M, Hirayama S, Lara-Guerra H, Anraku M, Waddell TK, Liu M, Keshavjee S: MMP-dependent migration of extrapulmonary myofibroblast progenitors contributing to posttransplant airway fibrosis in the lung. Am J Transplant 2009, 9:1027-1036

57. Lama VN, Phan SH: The extrapulmonary origin of fibroblasts: stem/progenitor cells and beyond. Proc Am Thorac Soc 2006, 3: 373-376 